
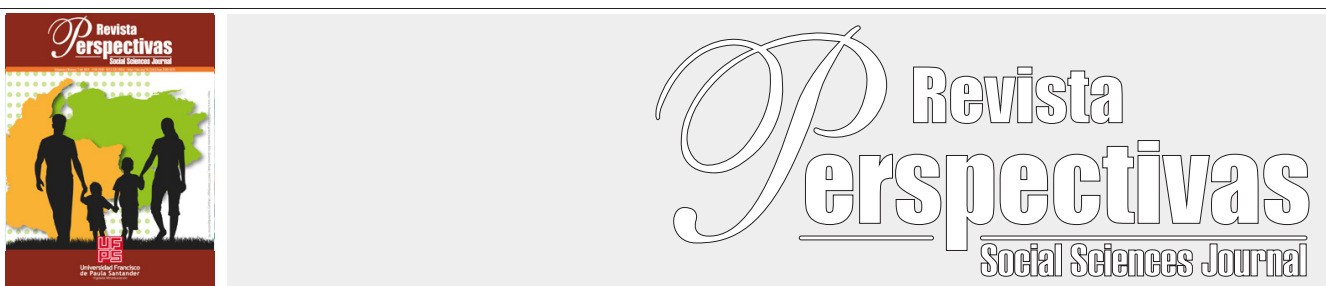

Artículo Original

https://doi.org/10.22463/25909215.2835

\title{
La restitución de tierras como reparación transformadora en la construcción de paz
}

Land restitution as transformative reparation in peace-building

Liany Yetzira Hernández-Granados ${ }^{1}$, Edward Fabián Latorre-Osorio² ${ }^{2}$ Karen Ximena Patiño-Pabón ${ }^{3}$, Jorge Luis MorenoCarreño ${ }^{4}$

${ }^{\prime}$ Magister, Universidad Francisco de Paula Santander, facultad de educación, artes y humanidades, programa de derecho, grupo de investigación en Justicia, Democracia y Derechos Humanos-JHUSDEM-, semillero de investigación en Derechos Humanos-SEMDHUM-, San José de Cúcuta, Norte de Santander, lianyyetzirahg@ufps.edu.co.

${ }^{2}$ Magister ,Universidad Simón Bolivar, Facultad Ciencias Políticas y Sociales, programa de Derecho, grupo de investigación altos estudios de la frontera, San José de Cúcuta, Norte deSantandere.latorre@unisimonbolivar.edu.co

${ }^{3}$ Estudiante, Universidad Francisco de Paula Santander, facultad de educación, artes y humanidades, programa de derecho, grupo de investigación en Justicia, Democracia y Derechos Humanos-JHUSDEM-, semillero de investigación en Derechos Humanos-SEMDHUM-, San José de Cúcuta, Norte de Santander, karenximenapp@ufps.edu.co.

${ }^{4}$ Estudiante, Universidad Francisco de Paula Santander, facultad de educación, artes y humanidades, programa de derecho, grupo de investigación en Justicia, Democracia y Derechos Humanos-JHUSDEM-, semillero de investigación en Derechos Humanos-SEMDHUM-, San José de Cúcuta, Norte de Santander, jorgeluismc@ufps.edu.co.

Cómo citar: L.Y Hernández-Granados, E.F. Latorre-Osorio, K.X. Patiño-Pabón, J.L. Moreno-Carreño, "La restitución de tierras como reparación transformadora en la construcción de paz”. Perspectivas, vol. 5, no. 2, pp. 105-116, 2020.

Recibido: August 30, 2019; Aprobado: Octubre 11, 2019.

\begin{tabular}{ll}
\hline & RESUMEN \\
\hline Palabras clave: & El presente artículo es el resultado del proyecto de investigación denominado: La Restitución de Tierras como \\
Reparación Transformadora en la Construcción de Paz, que surge como una iniciativa de los estudiantes del programa \\
Academia, \\
restitución de tierras, \\
reparación, \\
Humanos -SEMDHUM-, con el fin de despertar en la comunidad académica interés por la política de Restitución \\
de Tierras en el marco de la justicia transicional, con énfasis en el resarcimiento del daño y la restauración de los \\
concurso. & derechos de la víctimas del conflicto armado, especialmente las comunidades indígenas que sufrieron confinamiento, \\
abandono y/o despojo de sus tierras. Se promovieron una serie de estrategias de apropiación del conocimiento y \\
participación de los estudiantes en procesos académicos de desarrollo de competencias en esta área. Es por ello \\
que se auscultó sobre la condición de víctimas del conflicto de las comunidades indígenas, su pervivencia y el goce \\
de sus derechos, así mismo la jurisprudencia, normatividad y la necesidad de un enfoque diferencial en la política \\
pública de restitución de tierras. Igualmente se llevó cabo el foro denominado la Restitución de Tierras como \\
Reparación Transformadora en la Construcción de Paz, una capacitación sobre el enfoque étnico en el proceso \\
de Restitución de Tierras, comprendiendo la importancia que tiene para las comunidades indígenas la relación \\
con el territorio dentro de su cosmovisión y cosmogonía. Por último, y como resultado de las investigaciones, y \\
capacitaciones, los integrantes del semillero participaron en representación de la Universidad Francisco de Paula \\
Santander, en el II Concurso Regional interuniversitario "Restitución Transicional de Tierras para la Paz y la \\
Reconciliación", obteniendo la premiación al primer lugar y mejores oradores.
\end{tabular}

\begin{tabular}{|c|c|}
\hline & ABSTRACT \\
\hline $\begin{array}{l}\text { Academy, } \\
\text { land restitution, } \\
\text { reparation, } \\
\text { armed conflict, } \\
\text { competition. }\end{array}$ & $\begin{array}{l}\text { Santander University, members of the Research Seedbed in Human Rights -SEMDHUM-, in order to awaken in } \\
\text { the academic community interest in the Land Restitution policy within the framework of transitional justice, with } \\
\text { emphasis on compensation for damage and restoration of the rights of victims of the conflict armed, especially } \\
\text { the indigenous communities that suffered confinement, abandonment and / or dispossession of their lands. A } \\
\text { series of strategies for the appropriation of knowledge and the participation of students in academic processes of } \\
\text { competence development in this area were promoted. For this reason, the status of victims of the conflict of the } \\
\text { indigenous communities, their survival and the enjoyment of their rights, as well as the jurisprudence, regulations } \\
\text { and the need for a differential approach in the public policy of land restitution were auspicious. A forum called } \\
\text { Land Restitution as Transformative Reparation in Peace Building was also held, a training on the ethnic approach } \\
\text { in the Land Restitution process, understanding the importance of the relationship with the territory within the } \\
\text { indigenous communities. his worldview and worldview. Lastly, and as a result of the investigations and training, } \\
\text { the members of the seedbed participated in representation of the Francisco de Paula Santander University, in the II } \\
\text { Interuniversity Regional Contest "Transitional Restitution of Lands for Peace and Reconciliation", obtaining the } \\
\text { award to first place and best speakers }\end{array}$ \\
\hline
\end{tabular}

*Corresponding author.

E-mail address: lianyyetzirahg@ufps.edu.co (Liany Yetzira Hernández-Granados)

(c) (i) Peer review is the responsibility of the Universidad Francisco de Paula Santander. 


\section{Introducción}

El conflicto armado interno ha provocado la victimización de la población colombiana, principalmente en las zonas rurales, y especialmente en los grupos poblacionales más vulnerables, como lo son las comunidades indígenas, quienes gozan de especial protección constitucional; siendo necesario por parte del Estado la adopción de medidas normativas y de política pública que respondan específicamente a las afectaciones a su cultura, forma de vida y pervivencia, así como la comprensión de la integración y estrecho vinculo de las pueblos con su territorio, en consonancia con su cosmovisión y cosmogonía.

Es por ello, que la investigación desarrollada en el presente artículo propone la apropiación por parte de la comunidad académica de los conocimientos relacionados con el derecho fundamental a la restitución de tierras y la necesidad de la aplicación de un enfoque diferencial a las comunidades indígenas, por medio de actividades como foros, capacitaciones o la participación en concursos académicos, que promuevan la práctica y fortalecimiento de aptitudes en los estudiantes.

\section{Comunidades indígenas y su condición de vícti- mas del conflicto armado interno.}

El convenio 169 de la OIT de 1989 (ley 21 de 1991), establece las obligaciones del estado colombiano respecto a la protección de los derechos de los pueblos indígenas, en relación con su identidad cultural, autonomía, autoreconocimiento y su derecho fundamental a la propiedad colectiva del territorio.

A día de hoy, existe en la sociedad colombiana un desconocimiento de los grupos indígenas que se encuentran en el territorio nacional, al respecto la Organización Nacional Indígena de Colombia, ha manifestado sin lugar a dudas que
Estado colombiano a través de instituciones como la Dirección de Etnias del Ministerio del Interior y de Justicia, el Departamento Nacional de Planeación, el Ministerio de Defensa y el Departamento Nacional de Estadísticas, entre otras, pero no por todas ellas. En esta situación se encuentran 87 pueblos. Así mismo encontramos doce que son reconocidos por las organizaciones indígenas y finalmente tres que se auto reconocen desde su condición étnica y cultural'" (ONIC, 2016).

Los pueblos indígenas y las personas con identidad étnica indígena son sujetos de protección constitucional reforzada, en virtud de lo señalado en el artículo 13 de la Carta Política y, a su vez, titulares de derechos fundamentales en concordancia con los artículos 1, 7 y 70 idem, donde se promulgan los principios de participación, pluralismo, igualdad entre culturas y respeto a la diversidad étnica.

La Honorable Corte Constitucional en sentencia T-514 de 2009 resaltó que las comunidades indígenas son titulares de derechos fundamentales que no son asimilables a los derechos colectivos de otros grupos sociales, con un alcance jurídico y político, entre los que se encuentra el derecho fundamental de los pueblos indígenas al territorio. Sin embargo, se caracterizan por su situación de vulnerabilidad, debido a patrones históricos de discriminación, la amenaza de desaparición de sus costumbres, y la especial afectación del conflicto armado interno en relación con la apropiación de sus territorios y el desvanecimiento de su cultura.

El goce efectivo de sus derechos es responsabilidad directa del Estado colombiano, sin embargo, el escenario bélico que se ha presentado en el país, ha atentando de manera directa contra la permanencia y desarrollo pleno de su dignidad humana al impedírseles vivir como quieren vivir, vivir bien y vivir sin humillaciones, tres condiciones que concretan la vida digna $(\mathrm{CNMH}, 2014)$.

Durante más de medio siglo las acciones violentas se han inmiscuido en la forma de vida de

(...) En el territorio nacional habitan 102 pueblos indígenas,(...), algunos de ellos reconocidos por el 
dichas comunidades menoscabando sus derecho, sufriendo afectaciones directas hacia su vida, la persistencia de su cultura, su pervivencia y la relación o vinculo con su territorio, espacio donde pueden expresar aquello que las convierte en comunidades étnicamente diferenciadas, tal y como lo expresa el indígena Siona, luego de ser obligado a huir de su tierra: "Perder nuestra tierra es perdernos a nosotros, irnos es dar un paso hacia la muerte". (ACNUR, 2010).

Los territorios de las comunidades indígenas en la gran mayoría de los casos, se encuentran ubicados en zonas ricas en diversidad de recursos naturales y minerales (ACNUR, 2010), tales como lo son los biocombustibles, el petróleo y la madera, estando además situados en lugares próximos a las fronteras o pertenencia transfronteriza, por otro lado, estas características los hacen zonas de especial interés para fenómenos como el narcotráfico, dentro de las dinámicas del conflicto armado.

El desarraigo y amenaza a la pervivencia, que representa para los pueblos étnicos la separación con la madre tierra, se debe comprender en el contexto de su cultura, toda vez que su propia existencia y forma de vida se basa en la relación e integración con su territorio, en la cosmovisión y cosmogonía propia de las mismas, es decir, a su forma de ver e interpretar el mundo (Corte Constitucional, 2011), conforme al hábitat donde desarrollan sus tradiciones, creencias y rituales, así como los aspectos sociales, económicos y culturales de la comunidad, su integridad como pueblo depende de la permanencia en el territorio.

Igualmente, el concepto territorio no se restringe a la ubicación geográfica o al reconocimiento estatal mediante figuras como el resguardo, sino al espacio donde la comunidad realiza sus rituales, practican la caza y pesca, o donde ubican sus cementerios, es decir, el ámbito cultural, máxime al considerarse la ancestralidad como un título de propiedad (Corte Constitucional, 2011a), que se define por su carácter imprescriptible, inalienable e inembargable, en concordancia con los artículos constitucionales 58, 63 y 329. En el mismo sentido la Corte Interamericana de Derechos Humanos (CIDH, 2005) ha manifestado que no es necesaria la posesión de la tierra para que los pueblos indígenas reclamen la protección de su territorio.

En el año 2009 se registraron 32 pueblos indígenas en peligro de extinción, donde 18 pueblos contaban con menos de 100 individuos (ACNUR, 2011). Hasta el año 2011 se tenían registros oficiales de que aproximadamente el $2 \%$ de las personas desplazadas en el país pertenecían a comunidades indígenas, cuya ocurrencia se dio en su mayoría en razón a las disputas territoriales entre grupos armados, las amenazas contra la vida y la integridad física de sus miembros, la invasión de los territorios despojados por cultivos ilegales, y el uso para la explotación de recursos como minería e hidrocarburos. (ACNUR, 2011a).

En auto 004 de 2009 el Tribunal Constitucional, disertó sobre el impacto negativo y notorio que ha tenido el conflicto armado hacia las comunidades indígenas, resaltando que su protección se enmarcada en elámbito internacional por tratados internacionales que han sido ratificados por Colombia, así como el articulado constitucional. Igualmente evidencia como sus derechos fundamentales han sido atropellados en diversas ocasiones, desembocando en la desintegración familiar y comunitaria que se da a razón del homicidio de sus líderes y lideresas, así como también las amenazas y el reclutamiento forzado, entre otros.

Dentro de los daños colaterales, se presentan afectaciones ambientales, que dificultan la caza y la pesca dentro de las comunidades, causando así inseguridad alimentaria, y la imposibilidad de la autosostenibilidad, junto con los confinamientos y bloqueos que incrementan el número de muertes por desnutrición, sumándose a la violencia sexual y por motivos de género, la prostitución forzada, la instalación de minas antipersonas en su territorio y 
el homicidio selectivo de autoridades, tradicionales, maestros y promotores de la salud.

La necesidad de una política de restitución de tierras con enfoque diferencial.

El conflicto armado interno colombiano es uno de los más complejos en el mundo, tanto por su larga duración como por las dimensiones que abarca, así como la constante en su violencia. Más de 50 años de guerra han afectado nuestro territorio de forma estructural, han sido años dolorosos, con infinidad de victimas en la población civil, todos ellos afectados tanto en sus creencias como en sus realidades, aunque comparten las marcas y sobre todo el miedo ocasionado por un conflicto del cual difícilmente se podría nombrar una fecha exacta de inicio o encontrar su origen en una sola causa, pudiendo aludir entre ellas, a la exclusión social y olvido estatal, la desigualdad económica.

Sin embargo, un número importante de investigaciones se centran en el acceso a la tierra, la disputa por territorios y recursos estratégicos perpetrada por actores armados como una de sus principales causas. El abandono y/o despojo de tierras en Colombia ha dejado como desenlace la muerte de miles de colombianos, trayendo como consecuencia el desplazamiento forzado interno de millones de campesinos, indígenas, afrodescendientes y líderes sociales (Vargas Reina, 2010)).

Para comprender la magnitud del problema de las tierras, en relación con el conflicto armado interno y su repercusión en el desplazamiento forzado, es importante recordar los conflictos agrarios entre terratenientes y campesinos durante la década de los ochenta, que trajo como consecuencia: la concentración de las tierras, el fortalecimiento de los grupos armados y de la violencia como mecanismo de solución de conflictos, la derrota del movimiento reformista agrario y por supuesto la vulneración de derechos (CNMH, 2015).
Según el Alto Comisionado de las Naciones Unidas para los Refugiados, al término de 2017 , Colombia fue el segundo país con la mayor población desplazada, después de la República Árabe Siria (12,6 millones de desplazados forzosos sirios), con 7,9 millones de víctimas del conflicto, la mayoría de ellas desplazados internos (7,7 millones), de los cuales el $21,2 \%$ correspondía a población afrodescendiente, el $6,2 \%$ a población indígena y el $42,4 \%$ a niños, niñas, jóvenes y adolescentes (ACNUR, 2018).

Cuando la víctima de desplazamiento forzado abandona sus tierras, o en su defecto estas le son despojadas con ocasión al conflicto armado, el tejido social se rompe, se ven compelidas a separarse de una de las instituciones más relevantes de la sociedad: la familia, y a su vez dejar atrás la vida que hasta ese momento han construido, exponiéndose a múltiples vulneraciones de derechos.

Como respuesta a esta problemática se ha desarrollado un marco normativo y jurisprudencial que da respuesta a las víctimas de desplazamiento forzado, como la ley 387 de 1997 sobre atención, protección, consolidación y estabilización socioeconómica de los desplazados internos por la violencia; el decreto 250 de 2005 que configura el plan nacional para la atención integral a la población desplazada por la violencia. Igualmente diferentes pronunciamiento de la Honorable Corte Constitucional como la sentencia T-025 de 2004 que declara el estado de cosas inconstitucionales respecto a la deficiente atención a la población desplazada, el pronunciamiento T-821 de 2007 sobre los derechos fundamentales de la población desplazada.

En este contexto es que se le otorga relevancia a los procesos de justicia transicional para el resarcimiento de los derechos de las víctimas, Bick Ford (2005) ha señalado que la justicia transicional se puede definir como un campo de actividad e investigación enfocado en cómo afrontan las sociedades los legados de abusos pasados contra 
los derechos humanos, atrocidades en masa y otras formas de trauma social severo, incluyendo el genocidio o la guerra civil, con el fin de construir un futuro más democrático, justo o pacífico (pg.1045).

El objetivo de la justicia transicional es reconocer a las víctimas y promover iniciativas de paz, reconciliación y democracia, garantizando así; la verdad, la justicia, y la reparación con garantías de no repetición. Por las particularidades de los conflictos, y por supuesto por los actores que hacen parte de ellos, (víctimas y victimarios) sería imposible aplicar la justicia ordinaria, en consecuencia, la justicia transicional se presenta como una oportunidad a las sociedades que buscan generar un cambio en sí mismas después de un periodo de violación generalizada de los derechos humanos. Este enfoque surgió a finales de los años 80 y principios de los 90 , como respuesta a demandas de justicia en América Latina y en Europa oriental. (Centro internacional de justicia transicional 2009pg 1.)

Colombia cuenta con aproximadamente diez años de experiencia en la implementación y formulación de mecanismos de justicia transicional, durante los cuales se han impulsado políticas públicas y expedido distintas leyes bajo el marco de la justicia transicional, un ejemplo de ello, es la negociación política que emprendió el gobierno del entonces presidente Álvaro Uribe para la desmovilización de 31.472 combatientes de las llamadas Autodefensas Unidas de Colombia (AUC), el cual se hizo jurídicamente posible a través de la Ley 975 de 2005, conocida como Ley de Justicia y Paz.

Por su parte, en junio de 2011 se adoptó la Ley de Víctimas y Restitución de Tierras, que constituye un hito histórico en la atención y reparación integral de las víctimas en el país, es en mayor medida la creación de esta ley y el avance de la justicia transicional en Colombia, lo que hace posible el desarrollo del proceso de restitución de tierras como parte del marco de políticas públicas que buscan resarcir los daños de la población víctima del conflicto armado interno en Colombia. (Art. 1 Ley 1448 de 2011)

Es de vital importancia que el conflicto armado colombiano sea interpretado y regulado a partir de un enfoque diferencial con respecto a la población vulnerable, así como es pertinente establecer investigaciones y políticas públicas eficaces, exhaustivas e imparciales que contribuyan a la reparación integral de las víctimas (ET Ayala, EG Osorio-Sánchez), es por ello que la población desplazada goza de especial protección constitucional, al encontrarse en una situación de vulnerabilidad, especialmente la población rural, al ser la más afectada, con el abandono y/o despojo de sus tierras, y ante la pérdida de la administración o explotación de los predios; debido al aprovechamiento del contexto de violencia son perturbados en su propiedad, posesión u ocupación (Art.74 Ley 1448 de 2011).

La legislación se proyecta con la intención de brindar un tratamiento integral a las personas que individual o colectivamente hayan sufrido daños por hechos ocurridos a partir del $1^{\circ}$ de enero de 1985, como consecuencia de infracciones al Derecho Internacional Humanitario o de violaciones graves y manifiestas a las normas internacionales de Derechos Humanos, ocurridas con ocasión del conflicto armado interno (Art. 3 ley 1448 de 2011), a su vez son titulares del derecho fundamental a la restitución de tierras las victimas de abandono y/o despojo a partir del $1^{\circ}$ de enero de 1991, el reconocimiento legal de las víctimas representa un paso adelante en el ideal de construir una sociedad más democrática, justa, e incluyente.

El reconocimiento normativo es sólo el comienzo de un proceso enorme de restitución integral, sin embargo, la ley 1448 es reconocida a nivel mundial como un gran proyecto de reparación, reconocimiento y dignificación de las víctimas, según un estudio de la universidad de Harvard "se trata del proyecto de reparación más generoso, más ambicioso y complejo que cualquier otro programa 
de reparación" (ICTJ 2015; Sikkink et al. 2014 pg.61).

El proceso de restitución de tierras cuenta con dos etapas creadas a partir de un mecanismo mixto, que se desarrolla siguiendo los principios del debido proceso, las garantías y una acción judicial efectiva; en ese sentido, primero se debe agotar la etapa administrativa a cargo de la Unidad de Restitución de Tierras, y posteriormente la etapa judicial a cargo de la justicia especializada de restitución de tierras. En la primera etapa se documentan los casos y se decide sobre su inclusión o no en el registro de tierras abandonadas y/o despojadas forzosamente, y en la segunda etapa, si el caso es incluido en el registro de tierras; los jueces y magistrados especializados en restitución de tierras definen la situación de los predios y ordenan su restitución jurídica y material, junto con otras medidas que garanticen el derecho a la restitución. A su vez, también acompaña al proceso la etapa del postfallo; las instituciones deben cumplir las órdenes proferidas por los Jueces y Magistrados, señaladas en la Sentencia judicial. (Dejusticia \& Unidad de administrativa especial de gestión de restitución de tierras despojadas, 2016, p.80)

Por otro lado, el proceso de restitución de tierras debe trascender de la simple entrega del inmueble, debe comprender a las víctimas como el eje de la reparación y sujeto de derechos, con capacidad para decidir y participar activamente en el proceso, siendo quien conoce y vive su historia. Es necesaria la relación y comunicación entre profesionales y las comunidades, complementando, promoviendo y fortaleciendo los procesos, con una clara orientación desde abajo y, por tanto, reconstruir el tejido social con eficacia, más allá de metas, indicadores y resultados se ha de incluir a la comunidad, la vida cotidiana y el sentido construido por los sujetos colectivos e individuales de cada municipio en Colombia (Villa \& Insuasty 2015 pg 440).

En Colombia 1'378.884 habitantes son indígenas, lo cual corresponde al $3,4 \%$ de la población total del país (DANE, 2005). Están localizados en 710 resguardos, esto es, 228 municipios de 27 departamentos (DANE, 2005). Para las comunidades étnicas el territorio tiene un profundo valor ancestral. Representa su identidad, es considerado vital para su pervivencia social y ritual, y es a su vez la base de la ley del origen. Siendo el territorio un elemento tan esencial para la vida digna de las comunidades indígenas, estas se han visto en la obligación de defenderlo por años en medio del conflicto armado que ocasiona desplazamiento forzado poniendo en riesgo el territorio y con él la vida de las comunidades.

Es por lo que representa la madre tierra para las comunidades indígenas que el proceso de restitución debe aplicarse bajo el enfoque diferencial, respetando así la cosmogonía y cosmovisión de los pueblos indígenas. Así mismo, para lograr que se aplique el enfoque diferencial, se ha desarrollado un cuerpo jurídico especial que garantiza su protección bajo el reconocimiento de la diversidad étnica y cultural, reconocido por Colombia y otros estados.

Con ocasión a la ley de víctimas y restitución de tierras se expide el decreto ley 4633 de 2011, por medio del cual se dictan medidas de asistencia, atención, reparación integral y de restitución de derechos territoriales a las víctimas pertenecientes a los pueblos y comunidades indígenas. Conforme a lo establecido en los decretos ley étnicos el territorio es reconocido como víctima, en consecuencia, los pueblos y comunidades indígenas tienen derecho a una reparación colectiva o individual. (art.3 Decreto ley 4633 de 2011)

Dentro de este decreto ley se acuerda que el territorio debe ser comprendido como integridad viviente y sustento de la identidad y armonía, en virtud del lazo especial y colectivo que sostienen las comunidades con el mismo, sufre un daño cuando es violado o profanado por el conflicto armado interno y sus factores vinculados y subyacentes. (Art. 45 Decreto ley 4633 de 2011) Atendiendo, entre otros, a "la especial relación [...] espiritual que tienen los pueblos indígenas con su territorio" (art. 8 Decreto 
ley 4633 de 2011) o al "vínculo especial y colectivo que los une con la madre tierra" (art. 3 Decreto ley 4633 de 2011), la ley reconoce la importancia del territorio en tanto garante primordial de la pervivencia física y cultural de estos pueblos.

La restitución material es un fin esencial, para posibilitar el retorno de los pueblos indígenas a su territorio, no obstante, si el territorio se encuentra degradado ambientalmente, bajo amenaza, o riesgo inminente, la restitución debe remplazarse; debe demostrarse que en efecto es imposible que el pueblo indígena se desarrolle física y culturalmente en ese territorio. Bajo esas circunstancias, los pueblos indígenas deberán adquirir un predio de condiciones similares o iguales al que ya no es habitable, pero en ningún caso de restitución de territorios colectivos procede compensación económica. (Unidad Administrativa Especial de Gestión de Restitución de Tierras Despojadas, 2012).

La academia como promotora del derecho fundamental a la Restitución de Tierras de las comunidades indígenas

Uno de los principales objetivos de la academia es promover la investigación y difundir el conocimiento en la sociedad, es por ello, que este proyecto consideró de gran importancia generar interés en torno al derecho fundamental a la Restitución de Tierras, especialmente el enfoque diferencial aplicado a las comunidades indígenas, temas relacionados en líneas anteriores, y así mismo, incentivar la participación de los estudiantes universitarios en actividades académicas por medio de las cuales adquirieran conocimiento y fortalezcan sus aptitudes.

El diccionario de la real academia española señala que el término "apropiación" nos remite a la palabra apropiar que se refiere a hacer algo propio o adecuar algo a una cosa; en este sentido la apropiación social del conocimiento se plantea la transmisión del saber y su adecuación a la sociedad. Para Cipriano Barrio Alonso los planteamientos asociados en la práctica académica y de políticas públicas están encuadrados en las relaciones entre conocimiento y sociedad, donde el papel de los actores implicados ayuda a disolver la brecha aparente entre ciencia y sociedad.

Más allá del monopolio de los conocimientosy de los saberes, y de entenderlos como mercancías, estos deben ser entendidos como bienes comunes (Fagiolo, 2012, p.68), que debe ser distribuido equitativamente entre los miembros de una sociedad, transformando la realidad; la justicia social y el bienestar social. En la actualidad, no existe únicamente un problema de distribución de capital, sino también un problema de distribución de información, conocimiento y saber (Zuluaga Duque, 2019), por lo que la apropiación del conocimiento, ante todo, requiere aprendizaje social (Díaz, 2017, p.61), a la vez que, integra los saberes adquiridos a través de la evolución de la sociedad con las diferentes reflexiones que se tejen en los sectores sociales, económicos y productivos, especialmente en el sector educativo.

Cada estudiante se transforma en actor del conocimiento como individuos que se adaptan al entorno, al conocer, apropiar y aplicar los conocimientos como una estrategia educativa para construir una experiencia de apropiación social del conocimiento. La metodología utilizada comprendió estrategias de acción- reflexión las cuales surgen de la práctica social, generando una perspectiva crítica sobre la misma a fin de transformar la realidad (Freire, 1976).

Es por ello que se realizaron capacitaciones sobre la política pública de restitución de tierras, las comunidades indígenas como víctimas del conflicto armado interno y las etapas de un proceso de audiencia en restitución de tierras con talleres teórico prácticos, concluyendo con la aplicación de los conocimientos adquiridos por medio de la participación en el II Concurso Regional interuniversitario "Restitución Transicional de Tierras para la Paz y la Reconciliación". 
Todas estas estrategias resultan de relevancia para el ejercicio universitario porque atraviesa sus ejes misionales como son la investigación, docencia, extensión y gestión. Con este fin se llevaron a cabo encuentros educativos y pedagógicos como el foro denominado "La Restitución de Tierras como Reparación Transformadora en la construcción de Paz", que contó con la presencia de diversos expertos en la temática, y la participación de más de 180 asistentes.

Diversos panelistas expertos en el tema, presentaron aspectos relevantes en materia de Restitución de Tierras, entre los cuales se encuentran; el Dr. Edward Francisco Álvarez Tafur, quien se encarga de la dirección territorial de la unidad de restitución de tierras para Norte de Santander y Arauca, y el Dr. Benjamín Magistrado de la Sala Civil Especializada de Restitución de Tierras de Cúcuta.

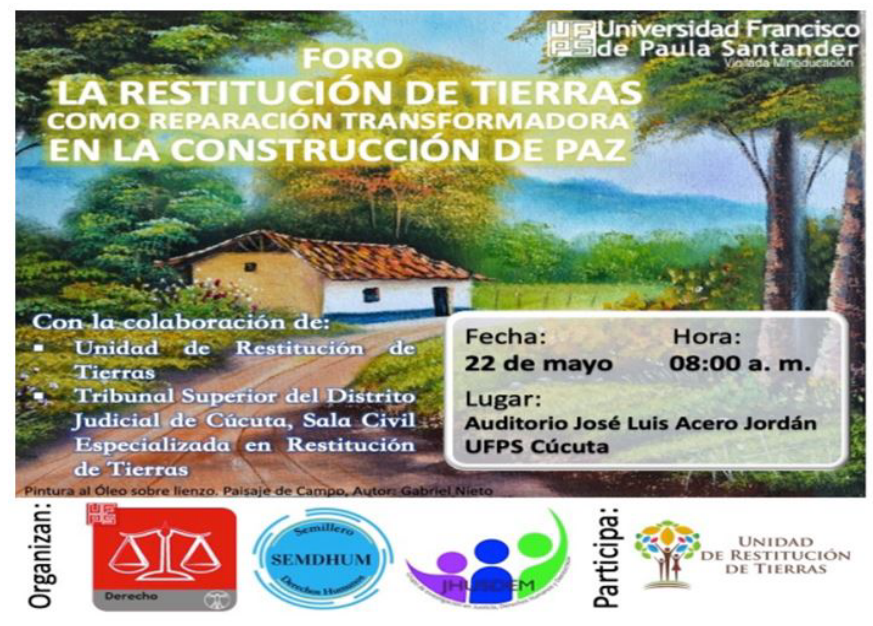

(Imagen publicitaria del foro).

Posteriormente se desarrolló una capacitación sobre el enfoque étnico en el proceso de restitución de tierras, nombrada "Restitución de Tierras con Enfoque Étnico", por medio de la cual los estudiantes adquirieron saberes sobre la cosmogonía y cosmovisión de los pueblos indígenas, la importancia del enfoque étnico en el proceso de restitución de tierras y como este está directamente relacionado con el valor que tiene el territorio para estas comunidades. Con el objetivo de dar un uso práctico a los conocimientos adquiridos a lo largo del desarrollo del proyecto, se llevó a cabo la participación en representación de la Universidad Francisco de Paula Santander en el II Concurso Regional Interuniversitario "Restitución Transicional de Tierras para la Paz y la Reconciliación”.

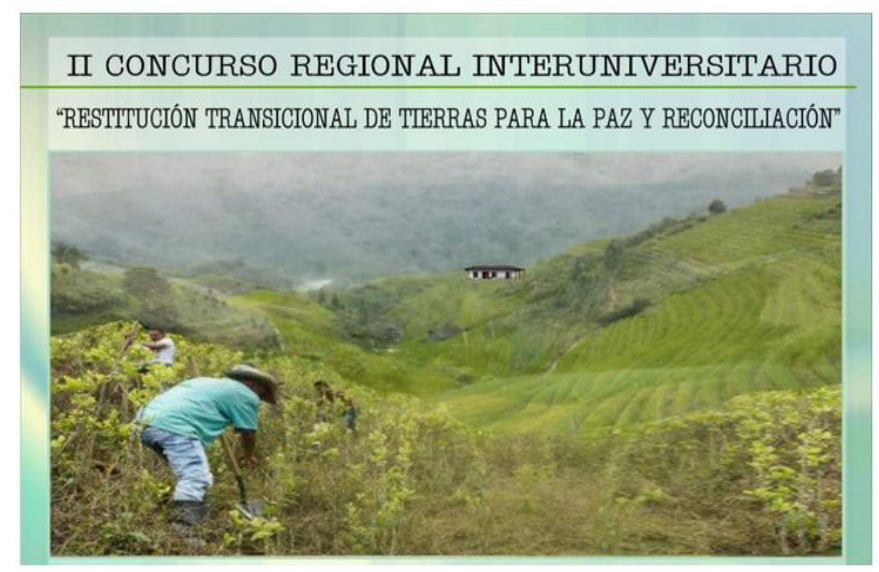

(Imagen publicitaria del concurso).

El concurso se desarrolló bajo la modalidad de MootCourt, esta modalidad implica un ejercicio académico donde se realiza la preparación, exposición y defensa legal de un caso hipotético. Generalmente consta de dos fases: una primera etapa es escrita y la segunda etapa se desarrolla de forma oral en audiencia simulada.

En la primera fase se presentan argumentos escritos y en la segunda argumentos orales en representación de cada rol, cada equipo asume un rol que es asignado por el comité administrativo y científico frente al caso hipotético asignado. En el II concurso interuniversitario los estudiantes del programa del derecho y miembros del semillero de investigación en derechos humanos -SEMDHUM-, cumplieron el rol de representación de la víctima de despojo y/o abandono forzado de tierras, que correspondía a la comunidad indígena MotilónBarí, siendo de gran importancia los conocimientos adquiridos en las capacitaciones previamente realizadas, y el rol de segundo ocupante que se trataba de campesinos en situación de vulnerabilidad, 
así como el rol de opositor representado por una empresa privada.

Participar en el concurso fue una experiencia enriquecedora, donde se compartieron experiencias con estudiantes de distintas universidades del país, se adquirieron conocimientos sobre el Proceso de Restitución de Tierras en todas sus etapas, y se llevaron a la práctica dichos aprendizajes, finalmente la representación de la UFPS obtuvo el reconocimiento al primer puesto y mejores oradores.

En la premiación se otorgó al equipo ganador un viaje a la capital, con el fin de conocer más de cerca algunas organizaciones que se dedican a la investigación, litigio y en general la defensa de los derechos humanos, con una marcada línea de trabajo centrada en el desarrollo y contexto de la ley 1448, tales como la Agencia de Cooperación Alemana GIZ, la Organización Dejusticia, la Comisión Colombiana de Juristas, la Procuraduría General de la Nación y la Unidad de Restitución de Tierras, quienes compartieron sus conocimientos, experiencias $\mathrm{y}$ bibliografía.

Producto de estas actividades se promovió y despertó el interés, no solo en lo que respecta al aprendizaje y concepción académica de todos los temas con relación a la restitución de tierras, sino también la necesidad latente de formar parte activa del cambio e impacto en la sociedad desde el punto de acción de la academia, en la formación de agentes de paz.

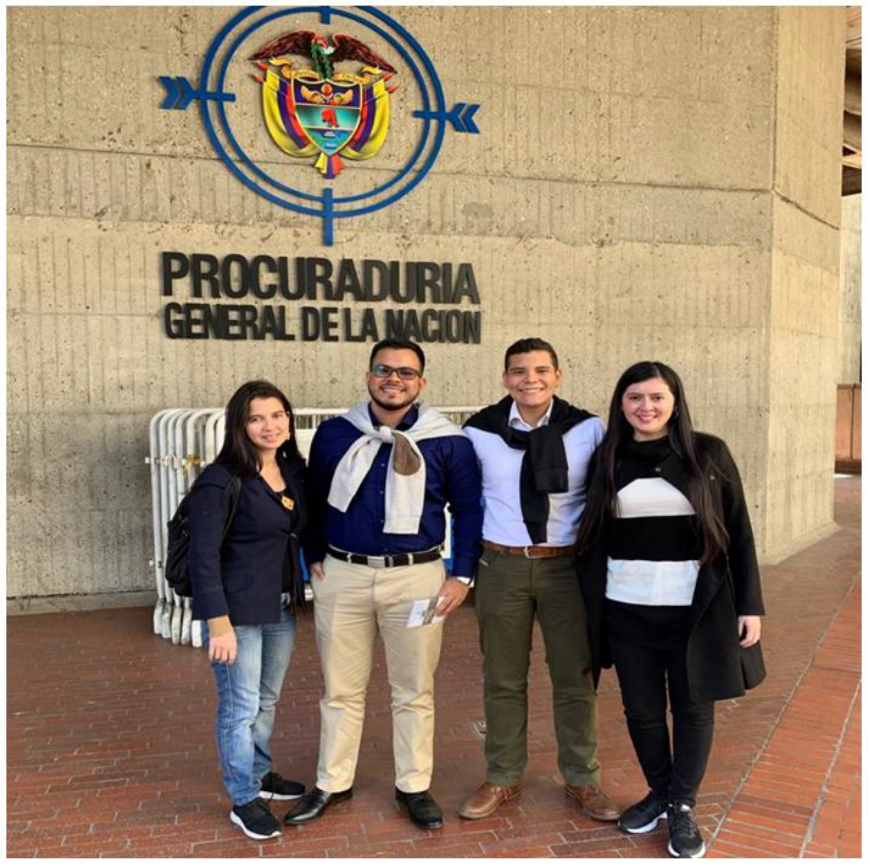

(Equipo ganador del II Concurso Regional interuniversitario "Restitución Transicional de Tierras para la Paz y la Reconciliación” en compañía de su tutora).

\section{Conclusiones}

- Colombia como escenario de un conflicto armado interno es uno de los países con mayor cantidad de población en situación de desplazamiento forzado, con múltiples vulneraciones a sus derechos humanos.

- El sistema jurídico colombiano, a través de sus normas y la jurisprudencia ha contemplado una serie de medidas para la atención, reparación y dignificación de las victimas de desplazamiento forzado.

- El abandono y/o despojo son delitos que padecen los desplazados internos, por lo cual, se hace necesario la restitución de sus tierras, por medio de los procedimientos y entidades creadas en el marco de la ley 1448 de 2011.

- Las comunidades indígenas son sujetos de especial protección constitucional, y a su vez 
población vulnerable afectada por el conflicto armado de forma diferenciada, debido a su estrecha relación con su territorio, su cosmovisión y su cosmogonía.

- El derecho fundamental de la restitución de tierras debe garantizarse a los pueblos indígenas victimas de abandono, despojo y/o confinamiento.

- La academia como promotora del conocimiento y responsable de incidir en la región donde se desenvuelve, adquiere el compromiso de realizar actividades que redunden en la capacitación, participación y adquisición de saberes y aptitudes enfocados en la restitución de tierras y la cultura de paz.

- La apropiación social del conocimiento por medio de practicas académicas y estrategias de acción reflexión promueve la transformación de la sociedad, la justicia social y ubica a los estudiantes como actores que conocen, apropian y aplican los saberes.

\section{Agradecimientos}

Este proyecto de investigación se pudo realizar gracias a la colaboración de la Unidad de Restitución de Tierras, el Tribunal Sala Civil Especializada en Restitución de Tierras de Cúcuta y la Agencia de Cooperación Alemana GIZ.

\section{Referencias}

Freire, P. (1976). La educación como práctica de la libertad (17 $\mathrm{a}$ ed.). México: Siglo XXI Editores.

Organización Internacional del Trabajo (OIT), Convenio (N. 169) sobre pueblos indígenas y tribales en países independientes, 27 Junio 1989, C169, recuperado de: https://www.refworld. org.es/docid/50ab8efa2.html [Accesado el 11 Abril 2020]Constitución política de Colombia. [Const.] (1991) 2da Ed. Legis.

Congreso de la República de Colombia (4 de marzo de 1991). Ley 21, sobre la Declaración de las
Naciones Unidas sobre los Derechos de los Pueblos Indígenas. [Ley 21 de 1991]. Recuperado de: http://www.renovacionterritorio.gov.co/ librerias/media/pdf/normatividad/Ley21_1991. pdf

Sala plena de la corte constitucional. (3 de febrero del 1997) sentencia Su-039/97 [MP Antonio Barrera Carbonell] Recuperado de: https:// www.corteconstitucional.gov.co/relatoria/1997/ SU039-97.htm

En Encyclopediaofgenocide, vol. 3, compilado por DinahShelton. Nueva York: McMillan, 2005: 1045-1047.

Departamento Administrativo Nacional de Estadísticas (2005). Censo general 2005 - nivel nacional. Bogotá

Corte Interamericana de Derechos Humanos (17 de junio de 2005). Caso de las comunidades Yakye Axa y Sowhamayaxa contra el Estado de Paraguay

Lesmes, Alvaro (Noviembre de 2006). El territorio, la otra mitad de ser Barí. Universidad Autónoma de Bucaramanga

Barrio Alonso, C. (2008). La apropiación social de la ciencia: nuevas formas. Revista CTS, $\mathrm{n}^{\circ} 10$, vol.4. Recuperado de: http://www.revistacts.net/ files/Volumen \%204\%20-\%20N\%FAmero\%20 10/doss 10.pdf

La Sala Tercera de Revisión de la Corte Constitucional. (30 de julio de 2009) sentencia T-514/09 [MP Luis Ernesto Vargas Silva]. Recuperado de: https://www.corteconstitucional. gov.co/relatoria/2009/T-514-09.htm

La Sala Segunda de Revisión de la Corte Constitucional. (26 de enero de 2009) auto 005 de seguimiento para la sentencia T-025/04 [MP Manuel José Cepeda Espinosa]. Recuperado 
de : https://www.corteconstitucional.gov.co/ relatoria/autos/2009/a005-09.htm

Vargas-Reina, Jenniffer. (2010). Guerreros y campesinos. El despojo de la tierra en Colombia. Estudios Socio-Jurídicos, 12(2), 381-387. Retrieved May 04, 2020, Recuperado de http:// www.scielo.org.co/scielo.php? script $=$ sci arttext\&pid=S0124-05792010000200012\&lng= en\&tlng=es.

Agencia de las Naciones Unidas para los Refugiados (2010). ACNUR "Perder nuestra tierra es perdernos nosotros" Los indígenas y el desplazamiento forzoso en Colombia (pp. 1-2). Recuperado de: https://www.acnur.org/fileadmin/ Documentos/RefugiadosAmericas/Colombia/ Los_indigenas_y_el_desplazamiento_forzoso en_Colombia.pdf

Congreso de la República de Colombia (10 de junio de 2011). Ley 1448 de 2011. Por la cual se dictan medidas de atención, asistencia, y reparación integral a las víctimas del conflicto armado interno y se dictan otras disposiciones

Unidad de Restitución de Tierras. Restitución de derechos territoriales étnicos: DecretoLey 4633 y 4635 de 2011 (p. 33). Recuperado de: https://www.restituciondetierras.gov.co/ documents/10184/34449/Restituci\%C3\%B3n + de + derechos + territoriales $+\% \mathrm{C} 3 \% \mathrm{~A} 9$ tnicos + Decretos+-+Ley+4633+y+4635+de+2011/880 9d630-8c57-45bc-bbe0-e96f3badc59f

La Sala Novena de Revisión de la Corte Constitucional. (31 de marzo de 2011) sentencia T-235/11 [MP Luis Ernesto Vargas Silva]. Recuperado de: https://www.corteconstitucional. gov.co/relatoria/2011/t-235-11.htm

Sala novena de revisión de la Corte constitucional. (12 de abril del 2011) sentencia T-282/11 [MP Luis Ernesto Vargas Silva]. Recuperado de:https://www.corteconstitucional.gov.co/ RELATORIA/2011/T-282-11.htm

Agencia de las Naciones Unidas para los Refugiados (2011). ACNUR. Situación Colombia: Pueblos indígenas (p. 1). Recuperado de: https:// www.acnur.org/fileadmin/Documentos/ Refugiados Americas/Colombia/Situacion_ Colombia_-_Pueblos_indigenas_2011.pdf

Agencia de las Naciones Unidas para los Refugiados (2011a). ACNUR. Situación de los pueblos indígenas en peligro de extinción en Colombia (p. 5). Recuperado de: https://www.acnur. org/fileadmin/Documentos/BDL/2011/7498. pdf? file $=\mathrm{t} 3 /$ fileadmin $/$ Documentos / BDL/2011/7498

Fagiolo, M. (2012). El conocimiento como bien común. CAYAPA, Revista Venezolana de Economía Social, 12(23), 65-83.

Unidad Administrativa Especial de Gestión de Restitución de Tierras Despojadas (2012) ABC para Jueces en Materia de Restitución de Tierras. Bogotá

Sikkink, Kathryn, Bridget Marchesi, Peter Dixon y Federica D'Alessandra. 2014. "Reparaciones integrales en Colombia: logros y desafíos. Evaluación comparativa y global". Harvard Kennedy School - Carr Center for Human RightsPolicy.

Triana García, D. (2014). Impactos Económicos del Conflicto Armado en Colombia: Análisis Departamental, 1990 - 2012 (p. 2). Medellín- Colombia. Recuperado https://repository.eafit.edu.co/bitstream/ handle/10784/8331/Daniel_TrianaGarcia_2014. pdf? sequence $=2 \&$ isAllowed $=y$

Centro Nacional de Memoria Histórica. (2014). Aportes teóricos y metodológicos para la 
valoración de los daños causados por la violencia (p.10).SantaFe deBogotá-Colombia.Recuperado de: https://www.bibliotecadigitaldebogota.gov. co/resources/2079009/

Centro Nacional de Memoria Histórica (2015). Una nación desplazada, ISBN 978-958-59068-7-7.

Dejusticia-equipo centro de estudio de derecho, justicia y sociedad \& Unidad de administrativa especial de gestión de restitución de tierras despojadas (2016) Modelo pedagógico. La restitución de tierras y territorios: justificaciones, dilemas y estrategias. Bogotá

Villa Gómez, Juan David, \& Insuasty Rodríguez, Alfonso (2016). Entre la participación y la resistencia: reconstrucción del tejido social desde abajo, más allá de la lógica de reparación estatal. EL ÁGORA USB, 16(2), 453-477.[fecha de Consulta 9 de Abril de 2020]. ISSN: 16578031. Recuperado de: https://www.redalyc.org/ articulo.oa?id=4077/407755354006

Villa Gómez, J., \& Insuasty Rodriguez, A. (2016). Significados en torno a la indemnización y la restitución en víctimas del conflicto armado en el municipio de San Carlos. El Ágora USB, 16(1), 165-191. Recuperado de https:/doi. org/10.21500/16578031.2171

Ayala, E. T., \& Osorio-Sánchez, E. G. (2016). La mujer como víctima y actor del conflicto armado en Colombia. Revista Perspectivas, 1(1), 73-80. Recuperado de https://doi. org/10.22463/25909215.972

ONIC - Pueblos indígenas. (2016). Revisado 11 Abril 2020, Recuperado de https:/www.onic. org.co/noticias/2-sin-categoria/1038-pueblosindigenas

Díaz-González, C. (2017). La apropiación social del conocimiento, un impulsor de la innovación: caso asociación Horfrubella, Pereira (Risaralda).
Revista Mutis, 7(2), 59-74. doi: https://doi. org/10.21789/22561498.1248

Alto Comisionado de las Naciones Unidas para los Refugiados (2018) tendencias globales: desplazamiento forzado 2017. ACNUR, 20 de junio. Recuperado de https://www.acnur. org/stats/globaltrends/5b2956a04/tendenciasglobales-desplazamiento-forzado-en-2017.html Bickford, Louis. "Transitional justice".

Zuluaga Duque, J. F. (2019). Apropiación social de los saberes: Hechos institucionales que hacen posible la generación de inteligencia colectiva. Revista Amauta, 17(34), 137-162. Recuperado de DOI: http://dx.doi.org/10.15648/am.34.2019.10 